\title{
RÉQUIEM PARA IVAN ILITCH: O PROBLEMA DA INTERPRETAÇÃO DO DIREITO NA LITERATURA DE TOLSTÓI
}

\section{REQUIEM FOR IVAN ILYICH: THE PROBLEM OF INTERPRETATION OF LAW IN TOLSTOY'S LITERATURE}

\author{
André Karam Trindade* \\ Luis Rosenfield ${ }^{* *}$
}

\begin{abstract}
RESUMO: o presente ensaio é parte dos resultados obtidos no projeto de pesquisa $O$ Direito na Literatura: a representação dos juízes nas narrativas literárias. Assim, com base nos pressupostos teóricos e metodológicos dos estudos do Direito na Literatura, aliados à noção de "modelo de juiz", formulada por François Ost, discute-se o papel do magistrado na novela A morte de Ivan Ilitch, de Lev Tolstói, publicada originalmente em 1886. Para tanto, reconstrói-se parte da história do direito czarista e, também, a conflituosa relação de Tolstói com a ciência jurídica. Ao final, propõe-se uma reflexão acerca da importância dessa novela do século XIX para a compreensão do problema da interpretação e da aplicação do Direito moderno.
\end{abstract}

PALAVRAS-CHAVE: A morte de Ivan Ilitch. Direito na literatura. Interpretação do direito. Lev Tolstói. Modelos de juiz.

ABSTRACT: This study is part of the results obtained within the research project Law in Literature: the representation of judges on literary narratives. Thus, based on the theoretical and methodological premises of Law in Literature, and on the notion of "model of judge", formulated by François Ost, it is discussed the role of the magistrate in the novella The death of Ivan Ilyich, by Leo Tolstoy, first published in 1886. It is made a reconstruction of part of the history of the tsarist law as well as of the conflictual relation between Tolstoy and legal science. At the end of this investigation, it is proposed a reflection on the importance of this novella from the XIX century for the understanding of the interpretative problem of modern law.

KEYWORDS: Interpretation of law. Law in literature. Leo Tolstoy. Models of judge. The Death of Ivan Ilyich.

SUMÁRIO: 1. Introdução. 2. Lev Tolstói e o Direito. 3. A morte de Ivan Ilitch: uma lição de Direito. 4. Réquiem para Ivan Ilitch? 5. À guisa de conclusão.

\footnotetext{
* Doutor em Teoria e Filosofia do Direito (Roma Tre/Itália). Mestre em Direito Público (Unisinos). Professor do Programa de Pós-Graduação em Direito da IMED. Coordenador do Kathársis - Centro de Estudos em Direito e Literatura. Presidente da Rede Brasileira Direito e Literatura (RDL). Editor-chefe da ANAMORPHOSIS - Revista Internacional de Direito e Literatura. Editor da Coleção Diante da Lei (Ed. Livraria do Advogado). Produtor Executivo do Programa Direito \& Literatura (TV Unisinos e TV Justiça). E-mail: andre.karam@imed.edu.br

** Mestrando em Direito (IMED). Membro do Kathársis - Centro de Estudos em Direito e Literatura da IMED. Secretário-executivo da Rede Brasileira Direito e Literatura (RDL). Editor-assistente da ANAMORPHOSIS - Revista Internacional de Direito e Literatura. Bolsista da Capes.E-mail: luis.rosenfield@gmail.com
} 


\section{INTRODUÇÃO}

O termo protagonista pertence, originalmente, à esfera dos estudos literários e designa a personagem principal de uma narrativa ou drama - que, embora se apresente, em geral, como o herói da história, pode, também, ser um anti-herói -, ao redor da qual se constrói toda a trama e de cuja ação dependem, direta ou indiretamente, os acontecimentos narrados ou encenados (CANDIDO, 1970; SILVA, 1986).

Na transposição para o campo jurídico, pode-se dizer que o termo protagonista não perde seu significado de origem, mas é sob a forma de uma derivação - mediante o acréscimo do sufixo ismo, que remete tanto à intoxicação de um agente quanto a movimentos sociais ou ideológicos - e associada a um adjetivo que surge a expressão protagonismo judicial, empregada para designar o juiz como a personagem que ocupa posição central no cenário do Estado Constitucional de Direito.

Sob a perspectiva da sociologia jurídica, por exemplo, é fácil observar o crescente poder que, a partir do final do século XX, os juízes e tribunais passam a exercer sobre a vida coletiva, seja em razão do aumento quantitativo e qualitativo da busca pela justiça como um dos efeitos da crise geral que assola a sociedade moderna, seja como fenômeno social mais amplo, em que a perda de referências e de valores representa um sintoma do declínio da família, do desaparecimento da religião como ícone moral e da falência das instituições tradicionais (GARAPON, 1996).

Isto se deve, como se sabe, à expansão do Poder Judiciário, ocorrida após a Segunda Guerra Mundial e impulsionada pelo teor das cartas constitucionais contemporâneas, que atribuíram um papel de destaque aos tribunais, ao guindá-los à condição de fiador dos direitos fundamentais e do regime democrático (TRINDADE, 2012).

Assim, o Poder Judiciário assume a função de guardião das promessas (GARAPON, 1996). Um dos efeitos deste protagonismo é, precisamente, o fenômeno da judicialização da política (TATE e VALLINDER, 1997; VIANNA, 1999), com o qual se verifica a transferência dos processos decisórios que pertenciam às esferas dos poderes Executivo e Legislativo para a esfera do Judiciário, de maneira que os juízes são, cada vez mais, chamados a intervir em questões controversas de natureza política (HIRSCHL, 2008).

Isso reabre a discussão acerca da legitimidade democrática dos juízes e, consequentemente, dos limites de sua atuação, uma vez que a ampliação dos espaços da jurisdição implica a redução dos espaços da legislação, aumentando ainda mais a tensão existente entre direito e democracia.

Todavia, no paradigma do constitucionalismo do segundo pós-guerra, houve uma profunda modificação do papel do juiz - recorde-se, aqui, da metáfora de Montesquieu, para quem o juiz era a boca-da-lei; ou, ainda, de Thomas Jefferson, para quem os juízes deveriam ser como simples 
máquinas (DALLARI, 2008) -, que antes se limitava a aplicar mecanicamente o direito, com base na noção rousseauniana de volonté générale sobre a qual se fundara a Revolução Francesa.

Ao contrário do modelo jacobino - para o qual o Direito reduzia-se à lei, enquanto a democracia consistia na submissão à vontade da maioria -, o paradigma do Estado Constitucional submete o exame da validade das normas jurídicas aos juízes e tribunais, em face da produção de um direito ilegítimo verificada durante os regimes totalitários (FERRAJOLI, 2007).

Neste contexto, portanto, em que a jurisdição constitucional torna-se uma peça fundamental da engrenagem do Estado Constitucional, é que os olhares se voltam para a figura do juiz (SPENGLER, 2011). Entretanto, salvo raras exceções, poucos ainda são os estudos e pesquisas sobre o protagonismo judicial e seus reflexos - especialmente, o ativismo - em terrae brasilis (STRECK, 2014).

E, aqui, precisamente, é onde a literatura - com suas narrativas, personagens e representações - e o imaginário social que ela produz e do qual, ao mesmo tempo, também resulta, podem ser utilizados para a compreensão do Direito.

Trata-se, com efeito, de uma vertente dos estudos jusliterários conhecida como Direito na Literatura (POSNER, 2009), a partir da qual se investiga de que modo os fenômenos jurídicos e as grandes questões ligadas à justiça são retratados pelas narrativas literárias ao longo da História. Tal corrente parte, na verdade, da premissa de que certas narrativas literárias são mais importantes para o estudo do direito do que a maioria dos tratados e manuais (TRINDADE e GUBERT, 2008; MARÍ, 1998).

Isso porque a literatura exsurge como um verdadeiro repositório de fontes para a reflexão crítica do direito. Além disso, serve como importante instrumento mediante o qual ocorre o registro histórico dos valores de determinado lugar ou época, na medida em que suas representações do poder, da lei e da justiça, por exemplo, também conformam o imaginário coletivo e social (OST, 2005; TALAVERA, 2006).

Assim, partindo dos pressupostos teóricos e metodológicos dos estudos do Direito na Literatura, aliados à noção de modelos de juiz - formulada por François Ost (1993), não obstante as contundentes críticas a ela dirigidas (STRECK, 2012, 2014) -, é possível analisar a representação do juiz e, de modo geral, das instituições ligadas à justiça, a partir de obras literárias.

Neste ensaio, propõe-se uma reflexão acerca do problema da interpretação e da aplicação do Direito moderno, levando em conta a representação do juiz - e, sobretudo, o papel por ele desempenhado (STRECK e TRINDADE, 2015; FÁBREGA PONCE, 2013; LAMY, 2001) - na 
novela A morte de Ivan Ilitch, de Lev Tolstói, escrita em 1886, em que se abordam questões que ainda hoje se encontram no centro da discussão do pensamento jurídico ${ }^{1}$.

\section{LEV TOLSTÓI E O DIREITO}

Em um clássico ensaio publicado em 1953, intitulado The Hedgehog and the Fox: An Essay on Tolstoy’s View of History, o filósofo Isaiah Berlin, com base em um aforismo do poeta grego Arquíloco - segundo o qual a raposa sabe muitas coisas, mas o ouriço sabe uma grande coisa -, divide e classifica os pensadores em duas categorias: raposas, para as quais a diversidade do mundo não pode ser explicada por meio de um único sistema, e ouriços, que são movidos por uma ideia central e que, portanto, explicam o mundo com referência a um único sistema. A título ilustrativo, Berlin inclui entre as raposas escritores como Shakespeare, Balzac, Goethe e Joyce, enquanto Dante, Dostoievski e Proust estariam entre os ouriços.

Tolstói seria precisamente o ponto fora da curva sobre o qual recai o ensaio de Berlin, eis que ele escaparia à definição proposta pelo filósofo inglês. Na verdade, Tolstói teria o talento e a habilidade de uma raposa, mas suas crenças seriam de um ouriço. Dito de outro modo, Berlin entende que Tolstói seria uma raposa por natureza, mas um ouriço por convicção.

Isto evidencia que Lev Nikolayevich Tolstói (1828-1910) foi um grande pensador e, certamente, um dos maiores escritores da literatura universal, cujos principais romances - Guerra e paz (1869), Anna Karenina (1877) e Ressureição (1889) - são de tal envergadura e solidez que se caracterizam, literalmente, por pararem em pé.

Sua obra é extensa e, em vários pontos, retrata uma série de questões jurídicas, políticas e sociais que caracterizam o século XIX e, de certa forma, antecipa problemas que atravessam o século XX, de maneira que suas narrativas constituem um terreno fértil para os estudos e discussões no campo do Direito e Literatura.

Na Espanha, por exemplo, desde o final do século XIX os juristas se utilizam de seus textos para análises jusliterárias (CALVO GONZÁLEZ, 2009). Os romances do autor retratam com profundidade uma série de questões políticas e sociais, o que proporciona ao leitor uma visualização precisa de certos aspectos da realidade oitocentista russa. À época, Tolstói já antevia problemas relacionados ao encarceramento de pessoas e às ínfimas chances de reabilitação após o

\footnotetext{
${ }^{1}$ Sobre esta obra, especificamente, houve a realização de um programa de televisão, Direito \& Literatura, exibido pela TV Justiça, em 2009, cujo debate, mediado por Lenio Streck, contou com a presença de André Karam Trindade e de Dino del Pino. O vídeo encontra-se disponível em: <https://www.youtube.com/watch?v=l891dHWLz-8>. Acesso em: 30 dez. 2014.
} 
cumprimento da pena. São igualmente dignas de nota suas reflexões sobre Direito Penal e Criminologia, em que são retratados diversos temas relativos à administração da violência institucionalizada (DELGADO-CINTRÓN, 2014; GAAKEER, 2005).

Todavia, para se entender determinadas implicações jurídicas na obra de Tolstói, convém revisitar, em razão de suas especificidades, e mesmo que rapidamente, a história do direito russo, a fim de elucidar algumas questões que subjazem à novela A morte de Ivan Ilitch. Tal apanhado histórico é fundamental para a compreensão do contexto em que Tolstói escreve a maior parte de seus textos (séc. XIX) e, sobretudo, para explicar o modo como o grande escritor russo se relacionava com o Direito.

Como se sabe, diferentemente da maioria dos países europeus, a Rússia é marcada por um retardamento na modernização de suas instituições e de seu ordenamento jurídico. Apenas com a subida ao trono de Pedro, o Grande (1689) - que inaugura o quarto período da história e do direito russo, cujo término ocorre somente com a Revolução Russa de 1917 -, é que a Rússia começa a desfazer um longo período de autoisolamento do resto da Europa e, gradualmente, retoma um contato mais estreito com o ocidente, reformulando suas instituições e seu modelo de administração pública (DAVID e HAZARD, 1954; MARQUES, 2003).

Isto não significa, entretanto, que o Direito tenha avançado de modo significativo. Tanto é assim que, nos reinados de Pedro I e de Catarina II (séc. XVIII), fracassou o projeto de revisão do “Código de Alexis II”, que era apenas uma compilação de leis ainda canônicas dos séculos XV e XVI (DAVID, 1998).

Na verdade, apenas em 1832, durante o reinado de Alexandre I, é que o célebre ministro Speranski foi encarregado de levar a cabo o movimento de modernização do Direito russo, consistente na codificação sistemática e eficiente, inspirada no modelo francês. Ocorre que, com a eclosão da guerra contra Napoleão - brilhantemente retratada em Guerra e paz - e a consequente reação de ódio aos franceses, o projeto não obteve a recepção positiva esperada, sobretudo pelo Conselho Imperial.

Por essa razão, aliás, é que, ainda na primeira metade do século XIX, em pleno reinado de Nicolau I, Speranski foi novamente chamado, desta vez para elaborar uma nova “compilação”, e não a tão almejada codificação do Direito russo. Essa compilação da legislação russa - vigente até a Revolução - era conhecida como Svod Zakonav Rossijskoj Imperii (Corpo das Leis do Império Russo). Para se ter uma ideia de sua dimensão, essa legislação era composta por 15 volumes e 42.000 artigos, e nas sucessivas edições superaram os 100.000 artigos, dos quais mais da metade era dedicada a matérias de Direito Público. 
Segundo David (1998, p. 149), pelo seu conteúdo eclético, pelo seu método casuístico e pelo seu espírito, o Svod Zakonav assemelha-se mais à legislação prussiana, de 1794, do que à codificação napoleônica. Isso porque a reforma legislativa atingiu apenas as fontes - e não o conteúdo - do Direito russo. Na verdade, o valor do Svod Zakonav reside, precisamente, na revogação das obscuras e arcaicas leis esparsas do Império Russo, o que modernizou, de certo modo, o corpus de normas vigentes (LOSANO, 2007, p. 165).

Destaca-se que somente na segunda metade do século XIX, durante o reinado de Alexandre II, é que se desenvolveu um movimento liberal de reforma. Esse movimento, além de resultar na elaboração de um Código Penal (1855), foi marcado principalmente pela abolição da servidão (1861) - que perdurou, de fato, até a Revolução Russa (1917) - e pela reforma da organização judiciária (1864), quando se separa a carreira da magistratura das carreiras administrativas e, finalmente, instituem-se tribunais profissionais. No entanto, a maior lacuna ainda era representada pela ausência de um Código Civil russo nos moldes das nações europeias ocidentais. Em 1882, houve a designação de uma comissão para sua elaboração. Tal objetivo, contudo, não foi atingido (DAVID, 1998).

Nesse momento histórico, parte significativa da aristocracia russa começa a atentar para a necessidade de mudança nas relações sociais por meio do direito. Esse esforço é mais bem ilustrado pela guinada que se estabelece na doutrina jurídica, principalmente por intermédio da abertura e da circulação doutrinária com as nações ocidentais mais desenvolvidas. Entretanto, ainda existia um amplo fosso entre a moderna teoria do direito e a prática jurídica da Rússia czarista. E, no final do século XIX, tal ponto de esgotamento tornara-se ainda mais evidente (LOSANO, 2007).

Esse é o panorama geral que domina o mundo jurídico russo durante a longa vida de Lev Tolstói. Como refere David (1998, p. 150), é possível identificar a ligação do Direito russo ao sistema romano-germânico. A ciência do Direito, por sua vez, segue muito de perto o padrão bizantino/romano e dos países que pertencem ao sistema romanista da Europa continental. Todavia, em plena modernidade, a Rússia ainda não estava completamente dotada de códigos como os outros países da Europa continental; ela ainda se preparava para ter códigos, pois lhe faltava uma tradição jurídica pujante.

Com efeito, a crítica de David chega ao extremo ao afirmar que não existiam verdadeiros juristas na Rússia até a segunda metade do século XIX²:

\footnotetext{
${ }^{2}$ Registre-se, por oportuno, que o Brasil segue um padrão similar àquele da Rússia quanto à criação tardia de seus cursos jurídicos. O Império brasileiro somente funda suas primeiras faculdades de Direito, as de São Paulo e de Olinda, em 1827, de maneira que a formação de juristas genuinamente brasileiros se dá apenas na segunda metade do século XIX, com o surgimento de intelectuais de grande envergadura como Pimenta Bueno, Tobias Barreto e Visconde do
} 
O mais grave não é o atraso, do ponto de vista técnico, do direito russo, nem o fato de ele só ter sido parcialmente codificado; o que importa sublinhar é que uma história diferente provocou no povo russo uma diferença de atitude perante o direito, contrastante com a dos outros povos europeus. Em toda a Europa continental, tal como na Inglaterra, o direito é considerado como um complemento natural da moral, e como uma das bases fundamentais da sociedade. Esta concepção do direito não se formou na Rússia. Até uma época recente, não houve juristas na Rússia: a primeira universidade russa, a de Moscou, só foi criada em 1755 e a universidade de Petersburgo, em 1802; uma literatura jurídica russa surge apenas na segunda metade do século XIX (DAVID, 1998, p. 151).

A partir dessa premissa, é interessante observar a ideia presente na obra de David (1998, p. 151), segundo a qual a unidade do povo russo não tem como base o direito. Ao contrário dos países ocidentais, onde seria inimaginável uma sociedade sem direito e sem tribunais - por mais criticáveis e falíveis que eles sejam -, tal pensamento não causaria estranheza na Rússia oitocentista.

Aliás, para ilustrar seu argumento, David cita expressamente o escritor russo, comparandoo a Santo Agostinho: “Tolstói preconiza o desaparecimento do direito e o advento de uma sociedade fundada na caridade cristã e no amor. O ideal marxista de uma sociedade comunista fraternal encontra raízes profundas no sentimento moral e religioso do povo russo” (DAVID, 1998, p. 152).

Mas qual a origem dessa descrença de Tolstói para com o Direito? Ou melhor: por que ele seria um “renegado do Direito”, como descreve Calvo González (2012, p. 128)?

A biografia de Tolstói nos permite especular as razões para seu ceticismo. Aos dezenove anos de idade, o futuro escritor cursava o segundo ano da Faculdade de Direito na Universidade de Kazan; período atribulado de sua vida, no qual tinha dificuldades em se integrar à vida universitária (BARTLETT, 2013). No início do curso, ele se interessou pelas disciplinas de Enciclopédia e Metodologia Jurídicas (algo equivalente às atuais Teoria e Filosofia do Direito). Todavia, ao final do ano de 1847, Tolstói abandona a faculdade. Apesar da tentativa de retomar o curso, um ano depois, em São Petersburgo, influenciado pelas leituras de Rousseau, ele renuncia de maneira definitiva à vida jurídica (CALVO GONZÁLEZ, 2012).

Um episódio interessante e pouco conhecido - transcrito em seus Diários, mas não registrado em edições comerciais - diz respeito à defesa por ele patrocinada de um soldado bêbado que atacara um oficial. No processo, conhecido como Caso Sabunin - no qual a acusação requereu a condenação à pena de morte -, Tolstói optou por não enfrentar o mérito e tentar afastar a pena capital, buscando atenuar a responsabilidade criminal. Sua estratégia fracassou. É possível que tal experiência - na qual Tolstói vivenciou o excessivo rigor que caracterizava a justiça militar da

Uruguai. Ou seja, somente depois da Independência é que começa a se desfazer a ligação com a Universidade de Coimbra e, assim, cria-se o ambiente para o florescimento de uma cultura jurídica brasileira pujante (LOPES, José Reinaldo Lima; QUEIROZ, Rafael Mafei Rabelo; ACCA, Thiago dos Santos. Curso de história do direito. São Paulo: Método, 2013). 
época - tenha contribuído para seu completo desencanto com o Direito (CALVO GONZÁLEZ, 2012, p. 123).

Como se sabe, com o passar dos anos, então, Tolstói defende uma espécie de “comunismo místico”, aliado à fé no amor e à teoria da não-resistência ao mal. Seu desgosto para com o Direito pode ser definido como um tipo de repulsa à ideia da força e do poder a serviço do Direito. Sua descrença é tamanha que ele defende a existência de uma essencial imoralidade do Direito. Essa desconstrução completa do Direito acentua-se durante a vida do escritor, que cada vez mais trabalha com conceitos baseados na noção de amor ao próximo. Na verdade, Tolstói aposta na ideia de Amor como Direito Supremo (CALVO GONZÁLEZ, 2012, p. 124).

Ao final de sua vida, sessenta anos depois de ter ingressado na Faculdade de Direito na Universidade de Kazan, Tolstói evidencia seu mais absoluto ceticismo e, pode-se dizer, desconfiança com o Direito. Num texto intitulado Carta a um estudante. Sobre o direito - que é a resposta à carta de um antigo discípulo, chamado Isaac Solomonovich Krutik, adepto da doutrina filosófica conhecida como tolstoísmo - encontra-se uma síntese da ácida e contundente crítica de Tolstói ao Direito e à ciência jurídica.

Nesta carta - resgatada por Calvo González e ainda inédita em língua portuguesa -, o escritor russo afirma considerar o Direito uma semiciência, de caráter fraudulento, que escravizava todos os povos europeus, advertindo seu pupilo:

\footnotetext{
Entregue há muitíssimos anos a outras ocupações, esqueci-me por completo da ciência do direito. Até mesmo tinha uma vaga ideia de que a maioria dos homens atualmente tivessem já se emancipado dessa fraude. Desgraçadamente percebo que, segundo sua carta, essa "ciência" existe e continua sua obra nefasta. Por isso me sinto feliz por ter tido a oportunidade de manifestar o que penso dessa dita ciência. Creio que sou o único que pensa assim.

Não aconselharia os "professores” dos diferentes "direitos”, que passaram toda sua vida estudando e ensinando essa mentira, e que graças a esse ensino criaram uma situação nas Universidades e Academias, imaginando-se muitas vezes e sinceramente que com ensinar suas "sobrevivências éticas", etc., fazem algo muito importante e útil; não aconselharia a esses senhores que abandonem sua ocupação delinquente. Como não aconselharia também aos padres, bispos e arcebispos, que também passaram toda sua vida a difundir o que creem necessário e útil. Porém a você, jovem, e a todos seus camaradas, não posso nada menos do que aconselhá-los que abandonem isso o mais breve possível, antes que gangrenem por completo, antes que o sentido moral se entorpeça totalmente em vocês, essa ocupação, não somente estúpida e embrutecedora, senão prejudicial e depravante (CALVO GONZÁLEZ, 2015).
}

Observa-se, assim, a existência de uma relação conflituosa e tumultuada de Tolstói com o Direito, que se deve em grande medida à relação ambígua do escritor com a estrutura do czarismo russo e com a vida aristocrática em geral. Todavia, nem sempre o posicionamento de Tolstói gravitou em torno dessa negação absoluta do Direito. Afinal, foi no convívio com um importante 
jurista da época, Anatóli Fiódorovitch Kóni, que Tolstói buscou a maior parte dos subsídios jurídicos para embasar sua literatura, somando-se às noções mínimas que possuía sobre o Direito, acumuladas nos quase dois anos em que estudou em Kazan e São Petersburgo (CALVO GONZÁLEZ, 2011, 2012).

Na verdade, a amizade com Kóni, um jurista liberal de alto nível intelectual - que também se relacionara intensamente com Tchekov e com Dostoievski -, abriu espaço para diversas ideias sobre temas de novos romances, como ocorreu em Ressureição, cujo enredo estrutura-se a partir de um caso real relatado por Kóni, misturando-se à própria jornada pessoal de Tolstói (BARTLETT, 2013, p. 465).

No entanto, ao menos a nosso ver, nem Ressureição, nem Anna Karenina são as narrativas de Tolstói mais interessantes para os juristas, mas sim a novela A morte de Ivan Ilitch, escrita em 1886 - e, portanto, na fase madura do escritor -, em que se pode encontrar uma verdadeira lição de Direito $^{3}$.

\section{A MORTE DE IVAN ILITCH: UMA LIÇÃO DE DIREITO}

Trata-se de uma novela cujo argumento central é a morte ${ }^{4}$ - embora, na verdade, a narrativa seja sobre a vida do protagonista (Nabokov, 2014, p. 292) -, o que, aliás, rende-lhe um grande interesse por parte dos médicos e demais profissionais da saúde (CECILIO, 2009). Como adverte o narrador (onisciente) na abertura do segundo capítulo: “A história da vida de Ivan Ilitch foi das mais simples, das mais comuns e portanto das mais terríveis” (TOLSTÓI, 1997, p. 19).

Tal qual ocorre no romance Memórias póstumas de Brás Cubas, de Machado de Assis (2008) - escrito em 1881, cinco anos antes da novela de Tolstói -, a narrativa se inicia com o relato da morte do protagonista. Ivan Ilitch Golovin é um juiz que integra a Corte Suprema e, acometido por uma enfermidade rara e desconhecida, morre aos 45 anos de idade, no dia 4 de fevereiro de 1882.

\footnotetext{
${ }^{3}$ Para Nabokov (2014, p. 292), “esse conto é a realização mais artística, mais perfeita e mais sofisticada de Tolstói”. Na mesma linha, em apêndice à edição traduzida por Boris Schnaiderman (Ed. 34, 2004), Paulo Rónai refere que muitos críticos consideram esta a novela mais perfeita da literatura mundial. Tal opinião também é compartilhada pelo escritor Dalton Trevisan, para quem “todo mundo morre duas vezes, e a primeira é quando lê Ivan Ilitch”.

${ }^{4}$ Registre-se, por oportuno, que tal temática já havia sido abordada por Tolstói anteriormente, em 1858, num conto intitulado Três mortes, em que uma aristocrata, um cocheiro e uma árvore encontram-se interligados, narrativamente, pela experiência da morte.
} 
Desde seu início, a novela traz uma série de hábitos e rituais ligados às instituições judiciárias, incluindo uma fiel descrição dos bastidores do mundo jurídico russo do século XIX ${ }^{5}$, especialmente no que diz respeito à formação e à ascensão de Ivan Ilitch na sua carreira:

Ivan Ilitch era le phoenix de la famille, como as pessoas costumavam dizer. Nem tão frio e formal quanto o irmão mais velho, nem tão rebelde quanto o mais jovem, era um simpático meio-termo entre os dois - um homem inteligente, educado, bem-disposto e agradável. Fora educado para o Direito, assim como o mais moço, mas este não havia terminado o curso, sendo expulso logo no início. Ivan Ilitch, ao contrário, formara-se muito bem. Como estudante, ele já era exatamente o que viria a ser para o resto da vida: um jovem muito capaz, alegre, sociável, de boa paz, embora rígido, no que considerava serem suas obrigações - e ele considerava suas obrigações o que quer que os superiores assim considerassem (TOLSTÓI, 1997, p. 20).

Filho de uma família aristocrata, tão logo conclui a faculdade, Ivan Ilitch ingressou no serviço público, assumindo o posto de secretário particular e emissário do governador de uma província. Após cinco anos, com a criação de novas instituições, ofereceram-lhe o cargo de juiz, em outra província.

Sua conduta como magistrado era irrepreensível e, desde logo, indicava uma carreira de sucesso. Ele sabia muito bem como se portar diante de seus compromissos oficiais. Entretanto, diferentemente de quando era secretário do governador, agora, na condição de juiz, Ivan Ilitch

\begin{abstract}
sentia que todos - todos sem exceção, até aquele mais importante e autossuficiente estavam em suas mãos e que lhe bastava escrever certas palavras em um pedaço de papel timbrado e esta ou aquela pessoa tão importante e autossuficiente seria trazida a sua presença na condição de acusado ou de testemunha, e que bastava que ele decidisse não lhe deixar sentar e a pessoa seria obrigada a permanecer de pé em sua presença e responder ao seu interrogatório. Ivan Ilitch nunca abusou de sua autoridade, ao contrário, tentava suavizar o peso desta. Mas a consciência desse poder e a possibilidade de amenizar esse efeito só aumentavam o fascínio pela posição que ocupava (TOLSTÓI, 1997, p. 24).
\end{abstract}

No exercício de sua função jurisdicional, propriamente, seguia um modelo legalista e absolutamente asséptico. Para ele, a interpretação do Direito resumia-se a uma aplicação mecanicista da lei:

Quanto ao trabalho em si - isto é, os julgamentos - Ivan Ilitch logo adquiriu a arte de eliminar todas as considerações irrelevantes ao aspecto legal e reduzir até mesmo o caso mais complicado a uma forma pela qual os fundamentos pudessem ser colocados no papel, excluindo completamente sua opinião pessoal e, o que era mais importante, cumprindo todas as formalidades (TOLSTÓI, 1997, p. 24).

Logo seu casamento passou a ser entendido com uma conveniência voltada à manutenção das aparências exigidas pelo senso comum. E, assim, "Ivan Ilitch ia transferindo o centro de

\footnotetext{
${ }^{5}$ A título ilustrativo, merecem destaque os seguintes efeitos imediatos ao anúncio da morte de Ivan Ilitch: (a) seus colegas passam a imaginar como será a rodada de transferências e promoções na carreira em razão da vaga aberta; (b) sua esposa busca descobrir se haveria algum modo de aumentar a pensão que receberá do governo (TOLSTÓI, 1997, p. 6-18).
} 
gravidade de sua existência da família para o trabalho” (TOLSTÓI, 1997, p. 28). Ao longo de sua carreira, ele foi sendo promovido: primeiro, a promotor público assistente; depois, a promotor público, em outra província; e, finalmente, saltando sobre seus colegas, a juiz do tribunal.

Ocorre que, ao fazer a mudança para a nova casa, quando instruía um empregado sobre como deveria ser pendurado um material, escorregou na escada e, embora fosse ágil e tivesse conseguido evitar a queda, bateu de lado na maçaneta da janela. O machucado doeu, mas logo passou.

Não obstante todos os problemas de ordem familiar, a vida de Ivan Ilitch seguia a rotina que ele planejara:

\begin{abstract}
levantava às nove horas, tomava seu café, lia os jornais, vestia seu uniforme e ia para o Tribunal. Lá chegando, caía imediatamente na sua rotina de trabalho e preparava-se para lidar com petições, processos e as sessões públicas e administrativas. Em tudo isso, fazia-se necessário excluir dali tudo o que contivesse vida dentro de si - o que sempre perturba o andamento normal das coisas oficiais. Não permitia qualquer tipo de relações com as pessoas que não as oficiais e, mesmo assim, no ambiente oficial. Por exemplo: um homem chega ansioso por uma determinada informação. Ivan Ilitch, por não ser o funcionário em cuja esfera repousa a matéria, não teria nada a ver com o caso, mas se o assunto do tal homem fosse de sua competência, qualquer coisa que pudesse ser resolvida com o papel timbrado, nesse caso então Ivan Ilitch faria tudo que estivesse ao seu alcance e, ao agir assim, pareceria estar tendo relações humanas e cordiais, obedecendo aos ditames do bom relacionamento social. Mas onde cessassem as relações oficiais, cessava também qualquer forma de contato [...] E Ivan Ilitch fazia tudo isso não apenas com leveza, prazer e perfeição, mas como quem realiza um trabalho artístico (TOLSTÓI, 1997, p. 40-1).
\end{abstract}

No entanto, com o tempo, Ivan Ilitch passa a se queixar de um gosto estranho na boca e de um desconforto no lado esquerdo do estômago. Embora inicialmente aqueles sintomas não remetessem a qualquer doença, logo ele passou a sentir dores e sua situação começou a piorar, o que o obrigou a consultar um médico famoso:

Seguiu-se tudo dentro do esperado, como sempre acontece. Houve o habitual período na sala de espera, a atitude importante assumida pelo médico - ele conhecia bem aquele ar de dignidade profissional; ele próprio o adotava no Tribunal -, os exames e as perguntas que exigiam respostas que levavam a conclusões óbvias e obviamente desnecessárias e o olhar grave, que queria dizer: "Deixe tudo conosco e nós resolveremos as coisas, nós sabemos tudo do assunto e podemos resolvê-lo para você, como faríamos com qualquer outra pessoa”. O procedimento todo era igual ao dos Tribunais. Os ares que ele adotava no Tribunal em benefício do prisioneiro, o médico adotava agora em relação a ele (TOLSTÓI, 1997, p. 46).

E, então, tudo aquilo que lhe pareceria tão familiar, todas aquelas formalidades, protocolos e procedimentos passaram a assumir outro sentido na medida em que Ivan Ilitch também mudara de lugar. Isso porque apenas uma coisa lhe importava. Ele queria saber do médico, afinal, se o seu caso era grave ou não. 
Mas o médico ignorou essa pergunta tão fora de propósito. Do ponto de vista do médico tratava-se de um detalhe que não merecia ser levado em consideração: o problema realmente era avaliar todas as probabilidades e decidir entre um rim flutuante ou apendicite. Não era uma questão de Ivan Ilitch viver ou morrer, mas de decidir se era rim ou apêndice. E nesse caso o médico inclinava-se mais em favor do apêndice, com a ressalva de que a análise da urina poderia indicar uma pista totalmente nova e então toda a questão teria de ser reavaliada. Tudo isso era, em menor proporção, exatamente o que Ivan Ilitch fizera de modo tão brilhante mil vezes ao lidar com as pessoas no Tribunal. O médico concluiu tudo brilhantemente, olhando triunfante por sobre os óculos para o acusado. A partir da fala do médico, Ivan Ilitch concluiu que as coisas não estavam bem, mas que para o médico e provavelmente para todas as outras pessoas isso não faria a menor diferença, enquanto que para ele era simplesmente terrível. E essa conclusão foi dolorosa, despertando-lhe um grande sentimento de autopiedade, e de amargura em relação ao médico que não se importava nem um pouco com uma questão tão importante (TOLSTÓI, 1997, p. 47).

Desde então, Ivan Ilitch seguia obstinadamente as orientações médicas. Ocorre que, apesar de todo seu esforço em acreditar que melhorara, sua situação era cada vez mais grave. Isso fez com que procurasse outros médicos. Alguns concordavam entre si; outros fizeram diagnósticos diferentes. O denominador comum entre todos eles é que nenhum dos tratamentos prescritos produzia quaisquer efeitos, enquanto a saúde de Ivan Ilitch mostrava-se cada vez mais debilitada. A doença era, portanto, incurável.

Ivan Ilitch estava morrendo. Ele sabia disso, porém parecia impossível acostumar-se com a ideia. Ele simplesmente não conseguia entender. E isso o desesperava:

O exemplo de um silogismo que aprendera na Lógica de Kiezewetter, "Caio é um homem, os homens são mortais, logo Caio é mortal”, parecera-lhe a vida toda muito lógico e natural se aplicado a Caio, mas certamente não quando aplicado a ele próprio. Que Caio, ser abstrato, fosse mortal estava absolutamente correto, mas ele não era Caio, nem um ser abstrato. Não: havia sido a vida toda um ser único, especial. Fora o pequeno Vanya, com mamãe e papai e Mita e Volodoya, com brinquedos e um tutor e uma babá; e mais tarde com Kátia e todas as alegrias e prazeres da infância, da adolescência e da juventude. O que sabia Caio do cheiro da bola de couro de que Vanya tanto gostava? Por acaso era Caio quem beijava a mão de sua mãe e escutava o barulho suave da seda de suas saias? Foi por acaso Caio quem se envolveu em protestos quando estudante de Direito? Foi Caio quem se apaixonou? Quem presidiu sessões como ele?

E Caio certamente era mortal e era mais do que justo que morresse, mas ele, o pequeno Vanya, Ivan Ilitch, com todos os seus pensamentos e emoções, é completamente diferente. Não pode ser verdade, isto seria terrível demais (TOLSTÓI, 1997, p. 63-4).

Após três meses da doença, já afastado de suas atividades no Tribunal, Ivan Ilitch convive com as dores à base de grandes doses de ópio e injeções de morfina. Sua relação com a esposa e os filhos torna-se insuportável. A única pessoa em quem encontra conforto e na presença de quem se sente um pouco melhor é o empregado Gerassim, que entende seu sofrimento e, sem qualquer interesse que não o bem alheio, faz de tudo para atenuá-lo.

O narrador relata que, “do momento em que começou a gritar, Ivan Ilitch prosseguiu por mais três dias e eram gritos tão horríveis que podiam ser ouvidos de porta fechada, dois quartos 
adiante” (TOLSTÓI, 1997, p. 98). No leito de morte, ele continua a refletir sobre a vida que tivera e, finalmente, se dá conta de que não vivera como deveria. Ao se perguntar "o que seria fazer a coisa certa?”, sentiu o filho mais novo lhe beijar e, então, compreendeu que ainda era possível dar um jeito. Sentiu pena do filho e também da mulher. Pediu que levasse o filho do quarto, disse à esposa que lamentava por ela e, já sem forças para dizer "perdoe-me”, fez um gesto com a mão, “sabendo que quem estivesse interessado entenderia” (TOLSTÓI, 1997, p. 100).

\section{RÉQUIEM PARA IVAN ILITCH?}

Tendo em vista o contexto da narrativa, percebe-se que a doença e a morte de Ivan Ilitch representam, metaforicamente, a enfermidade e o declínio da sociedade aristocrática russa do finde-siècle, em cujas bases se encontra o materialismo. Embora as aparências apontem sempre em sentido contrário, o País enfrenta graves dificuldades, especialmente no que diz respeito à desigualdade social extrema. As reformas institucionais postas em prática são de caráter meramente paliativo. Apesar de negada, a morte é iminente e somente pode ser compreendida sob uma perspectiva humanista. Trata-se, em suma, de uma alegoria que retrata a queda do Império russo, o que viria efetivamente a ocorrer, com a Revolução Bolchevique, algumas décadas mais tarde (CALVO GONZÁLEZ, 2012, p.126).

Mas, no que diz respeito à figura do juiz - e, sobretudo, ao papel por ele desempenhado -, qual a relevância desta novela de Tolstói para o Direito? Por que celebrar a morte de Ivan Ilitch, homenageando-o com um réquiem?

Como se viu, Ivan Ilitch é juiz russo da segunda metade do século XIX que encarna o típico papel de funcionário público da máquina estatal. Inteligente, ambicioso, competente e burocrático. Estas são algumas de suas principais credenciais. Sua atuação jurisdicional é pautada pela noção moderna de neutralidade. Para ele, independentemente da complexidade dos casos, sempre é possível reduzi-la mediante um procedimento capaz de enquadrar os fatos aos fundamentos legais. A aplicação do Direito - que, então, identificava-se com a lei - deve ser objetiva e cumprir todas as formalidades.

Observa-se, neste contexto, que - apesar da pré-modernidade do Direito russo neste período - Ivan Ilitch assume uma postura racionalista e formalista, o que, por um lado, certamente o aproxima do legalismo francês típico da Escola da Exegese ${ }^{6}$, embora sem a devida codificação e o

\footnotetext{
${ }^{6}$ Como se sabe, a Escola da Exegese é um movimento doutrinário marcado por assumir um tratamento científico do Código de Napoleão e reduzi-lo a comentários, artigo por artigo, de forma sistemática e metodológica. Tal escola - à qual se encontra associada a já referida clássica figura do juiz-boca-da-lei - é caracterizada por (a) identificar o direito
} 
pressuposto teórico da vontade geral; e, por outro, de maneira mais tímida, da lógica empregada pela Jurisprudência dos Conceitos ${ }^{7}$, em que pese o atraso no desenvolvimento da ciência jurídica e, portanto, da própria formação dos juristas.

Assim, mesmo não se tratando de um manual de história do pensamento jurídico, verificase que a novela de Tolstói permite identificar, facilmente, as doutrinas positivistas que inspiravam a atuação no tribunal e, de uma maneira mais geral, conformavam o próprio modo de ser de Ivan Ilitch. Como admite o protagonista, seu trabalho era decidir os processos judiciais sem se envolver com as pessoas e seus problemas, isto é, resolver abstratamente os casos, ignorando o mundo prático.

O maior exemplo de tudo isso ocorre, precisamente, quando Ivan Ilitch, na condição de paciente e, portanto, forçado a ocupar o lugar do outro (o débil, o fraco, o oprimido), percebe que os médicos o tratam do mesmo modo - onipotente e onisciente - como ele tratava as partes no Tribunal. A indiferença para com os pacientes é exatamente a mesma com que ele lidava com seus réus. Nesta situação, Ivan Ilitch dá-se conta de que suas preocupações não são as mesmas daquele que, desde outra posição, examinará seu caso. Por isto, suas perguntas não são levadas em consideração. Afinal, as respostas são despidas de qualquer humanidade, uma vez que dependem tão somente de procedimentos.

Na verdade, como bem ilustra a passagem na qual Ivan Ilitch resiste à (compreensão da) morte, o silogismo lógico - com base no qual ele próprio interpretava e aplicava, dedutivamente, as regras jurídicas, nos moldes do positivismo jurídico clássico - não poderia incidir no seu caso. Afinal, Caio era um ser abstrato e, portanto, poderia ser justo que morresse; ele, porém, não.

Assim, da maneira mais dolorosa, já no leito de morte, após uma profunda reflexão retrospectiva, Ivan Ilitch compreende que - ao contrário do que acreditara por toda a sua trajetória não viveu como deveria. E, certamente, isto se aplica à sua atividade jurisdicional, pois não se pode esquecer que, desde há muito, sua vida gravitava em torno do seu trabalho.

Muito embora seja tarde para colocar em prática, ao menos judicialmente, seu “aprendizado”, Ivan Ilitch reconhece que, ao exercer sua profissão como mero expediente

com a lei, (b) reduzir a interpretação à procura pela vontade da lei, recorrendo, quando necessário, à intenção do legislador, e (c) negar a existência de lacunas no sistema jurídico (BOBBIO, Norberto. O positivismo jurídico. São Paulo: Ícone, 1995; KAUFMANN, Arthur; HASSEMER, Winfried (Org.). Introdução à filosofia do direito e à teoria do direito contemporâneas. Lisboa: Gulbenkian, 2002).

${ }^{7}$ A Jurisprudência dos Conceitos, cujos principais expoentes são Puchta e Winscheid, surge em oposição à Escola Histórica do Direito. Trata-se, com efeito, da expressão mais acabada do estilo formalista e logicista que pensa e constrói o direito como um sistema de conceitos. As premissas sobre as quais se funda tal corrente são as seguintes: (a) o direito é considerado um sistema de conceitos, (b) a lei é a base e o ponto de partida da atividade que passa sucessivamente pela interpretação e construção de conceitos, (c) o sistema lógico-conceitual não contém lacunas (KAUFMANN e HASSEMER, op. cit.). 
burocrático, refém da lógica dedutiva, negligenciara a dimensão humana que é imprescindível a toda prestação jurisdicional.

Em suma, Ivan Ilitch descobre que, durante todo o período em que exerceu a função pública, especialmente a de magistrado, jamais se colocou no lugar do outro, sempre sob o álibi da neutralidade. Aliás, seu distanciamento não era apenas feito com prazer e perfeição, mas realizado como um verdadeiro "trabalho artístico". À medida que os médicos preocupam-se exclusivamente com sua doença, mas ignoram o paciente, ele se dá conta de que a empatia, a sensibilidade e, sobretudo, a humanidade não podem ser, de maneira alguma, eliminadas, principalmente quando se trata da realização da justiça. E nisto reside a lição de Ivan Ilitch, que deve ser homenageado mesmo que com um simbólico réquiem - como um juiz que, no final de sua vida, compreendeu a insuficiência da lógica para resolver casos práticos e difíceis no Direto e, assim, antecipou as críticas que seriam dirigidas ao positivismo legalista ao longo do século XX.

\section{4 À GUISA DE CONCLUSÃO: O JUIZ MODELO}

Muito embora não seja possível afirmar que Tolstói seja um escritor que tenha uma preferência por abordar temas e personagens jurídicos, Ivan Ilitch não é o único juiz que protagoniza sua vasta obra literária.

Na verdade, antes da novela A morte de Ivan Ilitch, Tolstói escreveu, entre os anos de 1859 e 1872, uma coleção de contos e fábulas para integrar o projeto pedagógico que implantaria em sua cidade natal, Yasnaya Polyana, no qual a leitura era considerada um instrumento indispensável para o processo de aprendizado das crianças.

Um desses contos - que pode ser uma interessante chave de leitura para a compreensão da figura do juiz na literatura de Tolstói - chama-se Um juiz modelo e foi publicado no Brasil, em 5 de novembro de 1897, no Diário Popular, de São Paulo (TOLSTÓI, 2011).

Neste conto, o juiz que protagoniza a narrativa é representado de uma perspectiva muito mais positiva do que aquela que, décadas mais tarde, assola Ivan Ilitch. Trata-se, aqui, de um juiz virtuoso. Vejamos, resumidamente:

A história provavelmente se passa na Argélia, tendo em vista iniciar com referência explícita ao Emir de Argel, de nome Bauakas, que resolve verificar se era verdade que, na capital da província, existia um juiz tão bom que, ao julgar, sempre descobria a verdade. Para tanto, o Emir se disfarçou de mercador e foi até a cidade do juiz. Durante o percurso encontrou um mendigo e, gentilmente, aceitou levá-lo em seu cavalo até o centro do povoado para onde se dirigia. Lá 
chegando, o mendigo recusou-se a descer do cavalo, alegando que o animal era sua propriedade. Pronto. Era o que o Emir precisava para ir à presença do juiz em busca da resolução do conflito. Antes de chamá-los, todavia, o juiz analisou outros dois casos. No primeiro, um sábio e um roceiro disputam a posse de uma mulher. O juiz mandou que deixassem a mulher e que retornassem no dia seguinte para a sentença. No segundo, um azeiteiro e um carniceiro discutiam a propriedade de uma moeda de ouro. O juiz ordenou que deixassem o dinheiro e que também voltassem no próximo dia. Então, chegou a vez de Bauakas. Ele e o mendigo contaram, cada um, a sua versão. O juiz ouviu-os atentamente e, ao final, pediu que deixassem o cavalo e regressassem como os demais. No dia seguinte, o juiz proferiu as sentenças: que o sábio levasse sua mulher, e o roceiro fosse açoitado; que o carniceiro levasse seu dinheiro, e o azeiteiro fosse açoitado. Para decidir o caso de Bauakas, porém, o juiz perguntou aos litigantes se eles seriam capazes de reconhecer o cavalo entre outros vinte. Ambos responderam afirmativamente e, ao procederem ao teste, identificaram o cavalo corretamente. Então, o juiz decidiu: que o mercador levasse seu cavalo, e o mendigo fosse açoitado. Perplexo, Bauakas pediu ao juiz que lhe esclarecesse como fazia para decidir tão sabiamente. Após explicar como procedera nos dois primeiros casos, o juiz respondeu que a disputa pelo cavalo era mais difícil e que o teste por ele proposto não era para que os litigantes apontassem seu cavalo, mas sim para que este reconhecesse o verdadeiro dono. Abismado, o Emir revela sua identidade e reconhece que atingiu seu propósito, oferecendo-lhe o que quisesse. Ao que o juiz responde: Não preciso de recompensas, considero-me plenamente satisfeito com os elogios do meu Emir.

Ora, neste conto, é possível observar que, ao desempenhar sua atividade, o juiz modelo está efetivamente preocupado em solucionar os problemas que lhe são trazidos. Prova disto é que, embora estejamos diante de uma metáfora, para cada caso concreto ele diligentemente cria um “procedimento” específico, voltado à elucidação dos fatos, de maneira que, ao final, possa ter os subsídios necessários para decidir corretamente.

Trata-se, em suma, daquele juiz que Ivan Ilitch compreendeu não ter sido ao longo de sua carreira. Um “modelo” que, alegoricamente, representa como é possível ao magistrado exercer a sua função em benefício da sociedade e, assim, construir respostas adequadas para os casos que lhe são apresentados, quando realmente compreende que a interpretação e a aplicação do Direito não podem negligenciar o mundo prático.

\section{REFERÊNCIAS}

ASSIS, Machado de. Memórias póstumas de Brás Cubas. Porto Alegre: L\&PM, 2008. 
BARTLETT, Rosamund. Tolstói: a biografia. São Paulo: Globo, 2013.

BERLIN, Isaiah. The Hedgehog and the Fox: An Essay on Tolstoy's View of History. London: Weidenfeld \& Nicolson, 1953.

BOBBIO, Norberto. O positivismo jurídico. São Paulo: Ícone, 1995.

CALVO GONZÁLEZ, José. Derecho y Literatura: Anatolii Fedorovich Kóni (1844-1927) (Sobre Cultura jurídica de la literatura y Cultura literaria del Derecho en la Rusia imperial de Alejandro II a Nicolás II). Seqüência, Florianópolis, n. 63, p. 13-76, dez. 2011.

. El alma y la ley: Tolstói entre juristas. España (1890-1928). Sevilha: Comunicación Social Ediciones y Publicaciones, 2009.

. El escudo de perseo. La cultura literária del derecho. Granada: Editorial Comares, 2012.

. Tolstói e o Direito. Sobre a educação jurídica. In: STRECK, Lenio Luiz; TRINDADE, André Karam (Ed.). Os modelos de juiz: ensaios de Direito e Literatura. São Paulo: Atlas, 2015.

CANDIDO, Antônio et al. A personagem de ficção. 2. ed. São Paulo: Perspectiva, 1970.

CECILIO, Luiz Carlos de Oliveira. A morte de Ivan Ilitch, de Leon Tolstói: elementos para se pensar as múltiplas dimensões da gestão do cuidado. Interface - Comunicação, Saúde e Educação, v. 13, supl. 1, p. 545-55, 2009.

DALLARI, Dalmo de Abreu. O poder dos juízes. 3. ed. São Paulo: Saraiva, 2008.

DAVID, René; HAZARD, John N. Le droit soviétique. Paris: LGDJ, 1954. 2 v.

DAVID, René. Os grandes sistemas do direito contemporâneo. Tradução Hermínio A. Carvalho. 3. ed. São Paulo: Martins Fontes, 1998.

DELGADO-CINTRÓN, Carmelo. Derecho y literatura. Visión literaria del derecho. Lima: Editoral San Marcos, 2014.

FÁBREGA PONCE, Jorge. Abogados y jueces en la literatura universal. Valencia: Tirant lo Blanch, 2013.

FERRAJOLI, Luigi. Principia iuris: teoria del diritto e della democrazia. Roma-Bari: Laterza, 2007.

GAAKEER, Jeanne. The art to find the mind's construction in the face: Lombroso's criminal anthropology and literature: the example of Zola, Dostoevsky, and Tolstoy. Cardozo Law Review, New York, v. 26, n. 6, p. 2345-78, 2005.

GARAPON, Antoine. O guardador de promessas: justiça e democracia. Lisboa: Instituto Piaget, 1996. 
GOMIDE, Bruno Barretto. Da estepe à caatinga. O romance russo no Brasil (1887-1936). São Paulo: Edusp, 2011.

HIRSCHL, Ran. The judicialization of politics. In: WHITTINGTON, K.; KELEMEN, R.; CALDEIRA, G. (Ed.). Oxford Handbook of Law and Politics. New York: Oxford University Press, 2008.

KAUFMANN, Arthur; HASSEMER, Winfried (Org.). Introdução à filosofia do direito e à teoria do direito contemporâneas. Lisboa: Gulbenkian, 2002.

LAMY, Alberto Sousa. Advogados e juízes na literatura e na sabedoria popular. Lisboa: Ordem dos Advogados, 2001. 3. v.

LOPES, José Reinaldo Lima; QUEIROZ, Rafael Mafei Rabelo; ACCA, Thiago dos Santos. Curso de história do direito. São Paulo: Método, 2013.

LOSANO, Mario G. Os grandes sistemas jurídicos: uma introdução aos sistemas jurídicos europeus e extra-europeus. São Paulo: Martins Fontes, 2007.

MARÍ, Enrique. Derecho y literatura. Algo de lo que sí se puede hablar pero en voz baja. Doxa Cuadernos de Filosofia del Derecho, Alicante, n. 21, p. 251-87, 1998.

MARQUES, Luiz Guilherme. A justiça e o direito na Rússia: reflexos da globalização. Jus Navegandi. Teresina, ano 8, n. 62, fev. 2003. Disponível em: <http://jus.com.br/artigos/3788>. Acesso em: 30 dez. 2014.

NABOKOV, Vladimir. Lições de literatura russa. São Paulo: Três Estrelas, 2014.

OST, François. Contar a lei. As fontes do imaginário jurídico. São Leopoldo: Unisinos, 2005.

Júpiter, Hermes y Hércules. Tres modelos de juez. Doxa - Cuadernos de Filosofía del Derecho, Alicante, n. 14, p. 169-94, 1993.

POSNER, Richard. Law \& Literature. Cambridge/London: Harvard University Press, 2009.

SILVA, Vítor Manuel de Aguiar e. Teoria da Literatura. 7. ed. Coimbra: Almedina, 1986.

SPENGLER, Fabiana; SPENGLER, Theobaldo. O direito, a literatura, o mito e o juiz: construções em torno do verbo decidir. RECHTD - Revista de Estudos Constitucionais, Hermenêutica e Teoria do Direito, São Leopoldo, v. 3, p. 102-10, 2011.

STRECK, Lenio Luiz. Lições de Crítica Hermenêutica do Direito. Porto Alegre: Livraria do Advogado, 2014.

. O pós-positivismo e os propalados modelos de juiz (Hércules, Júpiter e Hermes) - dois decálogos necessários. Revista de Direitos e Garantias Fundamentais (FDV), Vitória, v. 7, p. 1545, 2011. 
; TRINDADE, André Karam (Ed.). Os modelos de juiz: ensaios de Direito e Literatura. São Paulo: Atlas, 2015.

. Verdade e consenso: constituição, hermenêutica e teorias discursivas. 4. ed. São Paulo: Saraiva, 2012.

TALAVERA, Pedro. Derecho y literatura. Granada: Comares, 2006.

TATE, C. Neal; VALLINDER, Torbjörn (Ed.). The global expansion of Judicial Power. New York: New York University Press, 1997.

TOLSTÓI, Leon. A morte de Ivan Ilitch. Tradução Vera Karam. Porto Alegre: L\&PM, 1997.

TOLSTÓI, Lev. Um juiz modelo. In: GOMIDE, Bruno Barreto. Da Estepe à Caatinga. O romance russo no Brasil (1887-1936). São Paulo: Universidade de São Paulo, 2011. p. 590-92.

TRINDADE, André Karam. Garantismo versus neoconstitucionalismo: os desafios do protagonismo judicial em terrae brasilis. In: FERRAJOLI, Luigi; STRECK, Lenio; TRINDADE, André Karam. Garantismo, hermenêutica e (neo)constitucionalismo: um debate com Luigi Ferrajoli. Porto Alegre: Livraria do Advogado, 2012.

; GUBERT, Roberta Magalhães. Direito e Literatura: aproximações e perspectivas para se repensar o direito. In: TRINDADE, André Karam; GUBERT, Roberta Magalhães; COPETTI NETO, Alfredo (Org.). Direito \& Literatura: reflexões teóricas. Porto Alegre: Livraria do Advogado, 2008.

VIANNA, Luiz Werneck et al. A judicialização da política e das relações sociais no Brasil. Rio de Janeiro: Revan, 1999. 


\title{
REQUIEM FOR IVAN ILYICH: THE PROBLEM OF INTERPRETATION OF LAW IN TOLSTOY'S LITERATURE
}

\begin{abstract}
This study is part of the results obtained within the research project Law in Literature: the representation of judges on literary narratives. Thus, based on the theoretical and methodological premises of Law in Literature, and on the notion of "model of judge", formulated by François Ost, it is discussed the role of the magistrate in the novella The death of Ivan Ilyich, by Leo Tolstoy, first published in 1886. It is made a reconstruction of part of the history of the tsarist law as well as of the conflictual relation between Tolstoy and legal science. At the end of this investigation, it is proposed a reflection on the importance of this novella from the XIX century for the understanding of the interpretative problem of modern law.
\end{abstract}

KEYWORDS: Interpretation of law. Law in literature. Leo Tolstoy. Models of judge. The Death of Ivan Ilyich. 